ScienceDirect

BIOETHICS UPdate 4 (2018) 24-34
BIOETHICS UPdate

UNIVERSIDAD

PANAMERICANA

www.elsevier.es/bioethicsupdate

Original article

\title{
Individual Autonomy: Self, Culture, and Bioethics
}

Autonomía individual: persona, cultura y bioética

\author{
Ashwani Kumar Peetush ${ }^{\mathrm{a}, *}$, Arjuna Maharaj ${ }^{\mathrm{b}}$ \\ ${ }^{a}$ Departamento de Filosofia, Wilfrid Laurier University, 75 University Ave. W, N2L 3C5 Waterloo, \\ Ontario, Canada \\ ${ }^{\mathrm{b}}$ Escuela de Ciencia Interdisciplinaria, McMaster University, 1280 Main St. W, L8S 4L8 Hamilton, \\ Ontario, Canada
}

Received 27 June 2017; accepted 20 October 2017

Available online 6 December 2017

\begin{abstract}
This paper problematizes the concept of individual autonomy in the on-going project of attempting to understand and construct global principles of bioethics. We argue that autonomy as it is commonly defined and interpreted, and the emphasis that is placed on it, presupposes an individualistic concept of the self, family, and community that arises out of a Euro- Western liberal tradition and that is often in tension with various non-Western perspectives. We conclude that a more globally dialogical approach to bioethics is required.

(C) 2017 Centros Culturales de México, A.C. Published by Masson Doyma México S.A. All rights reserved.
\end{abstract}

Keywords: Bioethics; Medical ethics; Meta-ethics; Global ethics; Individual autonomy; Cultural diversity

\footnotetext{
* Corresponding author.

E-mail address: apeetush@wlu.ca (A.K. Peetush).
} 


\section{Resumen}

Este ensayo problematiza el concepto de autonomía individual con relación al proyecto en curso por comprender y construir principios globales para la bioética. Nuestro argumento es que la autonomía, tal como es corrientemente definida e interpretada, y el énfasis que se pone en ella, presupone una noción individualista de la persona y de la sociedad que deriva de la tradición liberal Euro-Occidental. Ese individualismo está frecuentemente en tensión con otras variadas perspectivas no occidentales. En conclusión, afirmamos la necesidad de una aproximación dialógica global a la bioética en general.

(C) 2017 Centros Culturales de México, A.C. Publicado por Masson Doyma México S.A. Todos los derechos reservados.

Palabras clave: Bioética; Ética médica; Ética global; Autonomía individual; Diversidad cultural

\section{Background}

It is becoming evident that a wide range of ethical theories, from environmental ethics to human rights and bioethics, uncritically privilege a particular constellation of views regarding self and agency that are parochial to Euro-Western cultures. Such theories are often grounded in epistemological and ontological assumptions that are in tension with a wide variety of non-Western ethical traditions. This is problematic since such theories are often purported to be universal and global in both scope and application. Recently several authors in bioethics have argued that many such ethical theories may not have the kind of sweeping universality as once purported. Nathan Cherny places emphasis on how cultural factors may allow for variations around certain ethical principles, namely voluntary diminished autonomy (Cherny, 2012). Gilbar and Miola also have expressed that the application of hitherto recognized ethical principles to patients of non-western cultural backgrounds may actually undermine self-determination rather than enhancing it (Gilbar \& Miola, 2015). Finally, Shimon Glick contends that while Western approaches to bioethics present themselves as canonical truth, it is important to be open and aware of the voices and contributions that global others may have to offer to bioethical thinking (Glick, 1997). While this research makes insightful contributions, we would argue that insufficient attention is paid to broader concepts of self and agency that underlie many of the ethical tensions discussed which we explore in this paper. 
Let us begin by illustrating such tensions by exploring two other fields before getting to bioethics. Many philosophical approaches to environmental ethics that are pitched as possible solutions to the current global environmental crisis frequently presuppose a view that conceptualizes the individual, self, and agency as entities that are separate and disconnected from nature and that have dominance over and above nature (Naess, 1985). Such views may be packaged in a broad array of disparate normative philosophical theories ranging from Kantian deontology, utilitarianism, to neo-liberal contractarianism. Despite deep disagreements about what makes actions right or wrong, such theories stand in stark tension with various non-Euro-Western perspectives. As an illustration, let us explore a spectrum of indigenous perspectives among First Nations in Canada - and indeed, around the globe. A common resemblance that runs throughout a multiplicity of Aboriginal perspectives view the self, in an important sense, as co-terminus with the environment. Indeed, the very notion of agency or what it is to be an ethical agent in the first place, is defined in terms of and intertwined with the whole notion of nature and eco-system. Land is not seen as private property; it is not thought to be a fungible entity that we can draw upon as mere material resource. Rather, it is conceptualized as part and parcel of one's very self (Allen, 1981; Tully, 1995). An ethics that arises out of such a perspective of self and world is architectonically distinct from the above dominant Western theories. In fact, one might argue that the current environmental crisis arises because of, as Charles Taylor has argued on many occasions, an atomistic notion of self that has come to be pervasive around the globe (Taylor, 1999). Ideas translate into action; how we understand the environment, our conception of it, affects how we treat it.

The same sorts of problems also arise with respect to human rights discourse (as an illustration of a problematic view grounded in an excessively individualistic approach, see Griffin, 2008). Indeed, a number of non-Western nations object that human rights, as articulated by the United Nations Charter, are not in fact universal. It is argued that the very idea of "human" rights is problematic. Human rights discourse assumes a view of agency in which the main kind of being that has any moral significance or value is limited to the human (hence "human" rights). Human beings stand apart from the rest of the world and occupy a special and distinct place (AnNa'im, 1992). This is not a global, universal, or cross-cultural notion. It certainly is in tension with various Indigenous, Buddhist, Hindu, Jain and Sikh standpoints. Many argue that we need to articulate the attempt at global consensus in terms of an ethic of well-being rather than "human" rights (Peetush, 2015).

The objection here, we should note, however, is not a rejection of the ethical norms that underlie human rights. It is not that somehow Aboriginal peoples or 
Buddhists do not have moral standards against rape or genocide or that they object to ethical principles. Rather, they approach and justify such principles from widely different meta-ethical perspectives and views of the self and world that need to be a part of a global discussion, since the aim is, after all, a truly cross- cultural and global consensus.

\section{Bioethics, Meta-Ethics, and the Self}

The three widely recognized axiomatic principles of bioethics are individual autonomy, beneficence, and justice. Most realize that the principle of justice has a wide degree of cultural and philosophical interpretation and this is thought to be legitimate (e.g., capitalist versus socialist). The same sort of acknowledgement however is not afforded to the principle of individual autonomy, which is often seen as somehow absolute (Beauchamp \& Childress, 2013). This particular weight usually assigned to autonomy arises out of the various multifaceted histories of Western liberal traditions (see e.g., early John Rawls, 1971 from whose work many such theories find their inspiration). On the face of it, the idea seems unproblematic at first blush: individual freedom is paramount to decision-making and is a prerequisite for informed consent. An individual has the right to decide for herself what she wants to do regarding medical treatment, according to her individual life plans, without interference from others. So then, what is the problem? We need to ask: to what exactly does the "individual," in "individual freedom" refer? That is, what sort of thing is an "individual," and what is an "individual's" relationship to other "individuals?" We argue that such notions are hardly benign and have profound implications for how we approach the practice of medicine.

To be clear, our point in this paper is not that individual autonomy is not relevant in non-Western contexts or that individual choice does not matter to non-Western peoples or that they homogeneously all share the same view of the self. This would be fallacious, to say the least. Nor is our purpose here to somehow "defend" various particular cultural perspectives or anything of that nature. We want to point out however that most dominant concepts of the self that emerge from Western liberal traditions are not usually globally and cross-culturally shared nor are they somehow neutral among various cultural positions. As Charles Taylor argues, they have their origins in the Kantian idea that human dignity primarily consists in individual freedom and rationality, or in an individual's capacity to choose a conception of the good life for himself, whatever that may be (Taylor, 1989, 1999). This is a strikingly distinct view, even in the history of the West. It extols the ability to make a choice 
as the highest ideal for an individual rather than the content of such a choice. This contrasts with earlier ancient Euro-Western perspectives themselves; according to a Socratic or Aristotelian viewpoint, certain ways of life are always better than others (e.g., a virtuous life of moderation is always better than a life of hedonism). It also contrasts starkly with most other cultural perspectives in which certain ethical values are held as ideals and others not (e.g., compassion, self-mastery vs. egoism, selfishness).

The liberal emphasis on individual freedom of choice has a corresponding ideal of the just society. Such a society is often conceptualized as an aggregate of independent self-interested rational individuals who group together for the sake of mutual selfinterest, with maximal individual freedom of each as the highest goal (limited only by freedom of others). The key and main role of the government, on this model, is procedural: it is to adjudicate competing demands of various individuals since interests often conflict. It is to remain neutral and stay out of discussions of ethical values (these are private matters). Such a society is highly individualistic in nature; shared goals are limited to an aggregation of individual interests (i.e., the need for a police station, or a fire station, and the like). Various common goods of a society are simply seen as reducible to convergent goods, grounded in individual self-interest. Concepts of self that animate this theoretical picture is that of an independent and self-contained ontological entity, with his own life plans, who stands in contractual (often adversarial) relationships with other individuals (Peetush, in press; Taylor, 1989, 1999).

The overemphasis and excessive focus on autonomy is not without issue however. The fetishization of the principle of autonomy as critical to the self in terms of our purported characteristic natures as "rational beings" excludes those among us who are mentally disabled, elderly, or young. Indeed, as Martha Nussbaum argues, for many of us, we are competent rational and autonomous agents in the Kantian and Rawlsian sense for only a segment of our adult lives, before we reach old age and become dependent - again - as we were when we were children (Nussbaum, 2006). This is not to mention the kinds of societal fragmentation that may result as the overemphasis on individualism grows: something that was readily seen in the 2008 financial crisis, where "ethics" becomes shorthand for and reduced to individualistic self-interest. As Callaghan argues, one of the reasons autonomy has been given a central place in ethical practice is because it champions this particular form of individualism (Callahan, 2003). Soren Holm points out that the key focus on autonomy reflects the moral values of America - namely individualism, and carries with it an inherent cultural bias (Holm, 1995). This inextricable tie between "respect for autonomy" 
and individualism has allowed the former to grow to prominence in medical ethics research.

We argue that although various "non-Western values" are certainly not homogenous or unchanging by any means, yet there is a constellation of values and views that are historically, socially, and philosophically pervasive in many such communities, such as India and China. This constellation contrasts highly with various former liberal conceptions of self. Communities are not seen as a mere aggregation of self-interested individuals, with each individual's freedom as the highest good. The family resemblances - whatever their differences (of which there are many, to be sure) - among such models, as Bhikhu Parekh argues, is that shared goals such as basic ethical values, filial piety, family values, and the like are also often a part of what is important in public policy, and not a matter somehow left to the private domain, as on a Rawlsian view (Parekh, 1994). Now, the idea of individual freedom that often undergirds such a constellation is different, because the concept of the individual, self and society are different. Parekh insightfully calls this a theory of “overlapping selves” (Parekh, 1994).

On an overlapping selves conception, individuals are seen as intrinsically embedded in the context of various close social and familial relationships and cannot be defined or instantiated in isolation from such relationships. Although individuals are distinct, selves are shared in common. That is, the boundaries of the body do not necessarily correspond to the boundaries of the self. What defines intimate relationships is that close others are not seen as distinct or separate from ourselves; rather they are part and parcel of our very being, our selves. Their interests are our interests, and as such, selves necessarily share goals in common that are not simply reducible to the convergent self-interests of "rational" agents.

The importance of a socially situated self is increasingly recognized. To illustrate, for example, Kevin Behrens argues that, in the context of various African communities, this idea is expressed by the notion of "Ubuntu" - that each person only becomes a person in the context of others (Behrens, 2017); each is inter-related as part and parcel of a web of social relations with significant others (Peetush, in press; Taylor, 1989). Shimon Glick describes Israeli society as at times individualistic but altogether "more as a community, even a family" (Glick, 1997). Each is inextricably interconnected and implicated in the life of the other and therefore decisions are more often taken in common. This is how decisions regarding marriage, career, and health are made. The decision-making procedure in such a context, as Parekh argues, is not nearly as individualistic as on the liberal model, but it is usually more democratic 
and cooperative. As Euro-Western traditions stress individual self-determination, Chen and Fan contend that various Eastern notions for respect for autonomy stress family-determination (Chen and Fan, 2010). Farhat Moazam captures this idea while describing the decision making process in Pakistan by stating, "you are your family and your family is you"(Moazam, 2000). Additionally, Chinese Confucianism echoes this belief as it contends that one's life is inseparable from those of their family.

In such a context, decisions regarding one's health and well-being (e.g., whether to undergo a certain procedure) are not decisions that are not solely a matter for the individual and his private interest. Rather, significant others are implicated in such decisions to an intimate degree. Of course, one should point out that this is certainly also true in the Western context. One might say that a key difference is that, for example, Indians and Chinese value individual freedom to a lesser degree than their Western counterparts. But we would point out that there are significant differences that cannot simply be captured as "matters of degree" and the degree to which individual freedom is prized. Often differences are matters of kind and involve competing accounts of self. The idea that, for example, marriage requires parents' input and consent, as an essential or necessary component of the decisionmaking process (although not sufficient), is seen to be an uncomfortable strain on one's individual freedom for the majority of Westerners - to say the least. For a large number of Indians and Chinese, this is not necessarily thought of as a strain at all since selves are interlinked and one's self is inextricably a part of a web of relationships rather than a discrete and independent entity with his or her private interests that chooses simply for him or herself.

In the context of bioethics, such issues translate into differences in practice at not only the level of how patients and families' see themselves and their rights and obligations as patients, but also how physicians understand their ethical duties to patients and their families. Informed consent, which is a prerequisite of individual autonomy, is not simply a matter of explaining to the "individual" patient his diagnosis, but understanding that consent is often shared across the family. Indeed, similar views are also an integral aspect of many African communities, as Behrens insightfully remarks: "decisions about one's body and life are. . not to be taken by individuals acting alone, but in an engagement with their families and communities. This is grounded in a strong sense of interdependence and mutual care (Behrens, 2017).”

As such, in an important regard, for the Asian, Indian, or African physician, the patient is not simply an individual that is unwell and needs to be brought back to 
health, she is more than that; the patient is the family, in its entirety, wholeness, and integrity. Along these lines, there are a variety of issues that arise with regard to informed consent and the family. For example, the notion of truth-telling is an integral part of informed consent as one needs accurate information to make a decision. This is an absolute principle in Western countries and has major legal ramifications. Yet this is a complex issue in many Asian cultures. In many such cultures, in the context of a terminal illness, many families prefer that patients not be told the truth of the diagnosis.

Indeed, a 1994 survey in the Japanese Journal of Clinical Oncology revealed that only one in five cancer patients were informed of their diagnosis (Benowitz, 1999). Korean gastroenterologist Hie-Won Yvonne L. Hann, M.D., professor of medicine at Jefferson Medical College of Thomas Jefferson University, Philadelphia, argues that whether and how she discusses a cancer diagnosis depends upon the cultural background of the patient and her family. In fact, as Steven Benowitz points out, in both Korea and Japan, "both doctor and family often decide on the appropriate cancer therapy and management with little say from the patient (Benowitz, 1999)." Jimmie C. Holland, M.D., who pioneered the field of psycho-oncology, argues that physicians need to understand that not telling the truth is a serious issue for some patients in Asian countries; it literally can determine the course of illness and health as it influences how patients understand disease and how they cope with it. What is interesting here is that families see this as protecting the patient, and, therefore, they see themselves as entitled to make such a decision. As Nathan Cherny argues, excessive candour in certain situations where it is not desired may be deemed as an "assault of truth" (Cherny, 2012).

What we want to emphasize with regard to such a key issue as truth-telling the different account of self and agency at work. The family may play such a critical role in the decision-making procedure for the patient (to the extent that he may not even know of his terminal illness) that "individual autonomy," as defined and interpreted in many Euro Western contexts may be near absent. We would urge that, in such a context, people may be working with a different account of autonomy, self and agency altogether, where responsibility is shared across a nexus of fluid and intertwined selves. Yet, the family does not see itself as impeding or "interfering" with the individual patient's freedom, informed consent, or the "right to know," but quite the opposite. They actually see themselves as enhancing the patient's freedom by alleviating the anxiety and stress associated with the knowledge of a terminal illness. 
We are certainly not advocating not telling patients about the full extent of their illness in Western countries. However, on the other hand, as Nathan Cherny, and R. Gilbar and J. Miola, contend, what is required is a more nuanced and subtle approach to understanding individual autonomy in the context of the culturally plural environments that both patients and physicians currently face (Cherny, 2012; Gilbar \& Miola, 2015). Furthermore - critically - as Gilbar and Miolo emphasize, our legal norms must change to keep pace with these better understandings of such contexts, to protect both the patient and doctor. Certainly, in many Western countries, where ideas of socially situated forms of relational autonomy may not be as prevalent among various community members, a legal framework needs to be in place that will allow doctors to appreciate such practices and attempt to accommodate such views without the fear of a lawsuit.

The goal in terms of individual autonomy is self-determination, yet selfdetermination is not some axiomatic mathematical principle in some abstract Socratic realm of the Good, rather it leaves and breathes. It arises organically out of our lived experiences as members of communities, as parts of relational and intersectional identities, histories, cultures and languages that make us who we are. In a global environment, if we are to provide the best medical care possible, we need to engage in substantive discussions about the good, and not limit ourselves simply to procedural rules that purportedly appear to take everyone's interests into account but in actuality fail to resonate with three quarters of the globe. We need to avail ourselves of the rich diversity and breadth of such understandings of self, agency, family, and community - undergirded, of course, by proper legal frameworks - so that patients' lives can truly be self-determined.

\section{Conclusion}

In the context of the on-going dialogue and attempt to construct principles of bioethics in a globally diverse environment, our aim in this paper was to problematize the notion of individual autonomy as it is traditionally understood. The degree of weight that is given to autonomy and the concepts of self and agency that often undergird it are not necessarily shared in a global context; they may be defined, interpreted, balanced, and/or prioritized in a manner that gives rise to various sharp tensions. Our goal was to articulate such differences and to bring to light that there are indeed other cultural perspectives that need to be considered if the claim to universality in scope and application in bioethics is to be genuine and accurate. Such an admission is predominantly absent from a majority of Western research in the field. We urge 
that a plurality of cultural perspectives need to become an intrinsic part of the global dialogue in the attempt to construct grounding principles in the growing field of bioethics so that patient care can be truly self-determined.

\section{Conflicts of interest}

The authors have no conflicts of interest to declare.

\section{References}

Allen, P. G. (1981). It goes this way. In G. Hobson (Ed.), The remembered Earth: An anthology of contemporary Native American literature (pp. 191-193). Albuquerque: University of New Mexico Press.

An-Na'im, A. A. (1992). Towards a cross-cultural approach to defining international standards of human rights: The meaning of cruel, inhuman, or degrading treatment or punishment. In A. An-Na'im (Ed.), Human rights in cross-cultural perspectives (pp. 21-43). Philadelphia: University of Pennsylvania Press.

Beauchamp, T. L., \& Childress, J. F. (2013). Principles of biomedical ethics (7th ed.). New York: Oxford University Press.

Behrens, K. G. (2017). A critique of the principle of 'respect for autonomy', grounded in African thought. Developing World Bioethics.

Benowitz, S. (1999). To tell the truth: A cancer diagnosis in other cultures is often a family affair. Journal of the National Cancer Institute, 91(22), 1918-1919.

Callahan, D. (2003). Principlism and communitarianism. Journal of Medical Ethics, 29(5), 287-291.

Chen, X., \& Fan, R. (2010). The family and harmonious medical decision making: cherishing an appropriate Confucian moral balance. J Med Philos, 35(5), 573-586.

Cherny, N. I. (2012). Controversies in oncologist-patient communication: A nuanced approach to autonomy, culture, and paternalism. Oncology (Williston Park), 26(1), 37-43, 46.

Gilbar, R., \& Miola, J. (2015). One size fits all? On patient autonomy, medical decision-making, and the impact of culture. Medical Law Review, 23(3), 375-399.

Glick, S. M. (1997). Unlimited human autonomy - A cultural bias? New England Journal of Medicine, 336(13), 954-956.

Griffin, J. (2008). On human rights. Oxford/New York: Oxford University Press.

Holm, S. (1995). Not just autonomy - The principles of American biomedical ethics. Journal of Medical Ethics, 21(6), 332-338.

Moazam, F. (2000). Families, patients, and physicians in medical decision making: A Pakistani perspective. Hastings Center Report, 30(6), 28-37.

Naess, A. (1985). The world of concrete contents. Inquiry, 28(1), 417-428.

Nussbaum, M. C. (2006). Frontiers of justice: Disability, nationality, species membership. Cambridge, MA: The Belknap Press/Harvard University Press.

Parekh, B. (1994). Superior people: The narrowness of liberalism from Rawls to Mill. Times Literary Supplement, 25.

Peetush, A. (2015). Human rights and political toleration in India: Multiplicity, self, and interconnectedness. In A. Peetush, \& J. Drydyk (Eds.), Human rights: India and the West (pp. 205-230). New Delhi: Oxford University Press.

Peetush, A. K. (2017). The Ethics of Interconnectedness: Charles Taylor, No-Self, and Buddhism. In G. Davis (Ed.), Ethics without self, dharma without atman: Western and Buddhist philosophical traditions in dialogue. Springer International Publishing (in press). 
Rawls, J. (1971). A theory of justice. Cambridge, MA: Bellknap Press.

Taylor, C. (1989). Sources of the self: The making of the modern identity. Cambridge, MA: Harvard University Press.

Taylor, C. (1999). Conditions of an unforced consensus on human rights. In J. R. Bauer, \& D. Bell (Eds.), The East Asian challenge for human rights (1st ed., pp. 124-144). Cambridge, UK/New York: Cambridge University Press.

Tully, J. (1995). Strange multiplicity: Constitutionalism in an age of diversity. Cambridge/New York: Cambridge University Press. 